\title{
Presurgical nasoalveolar remodeling - an experience in the journey of cleft lip and palate
}

This article was published in the following Dove Press journal:

Clinical, Cosmetic and Investigational Dentistry

30 December 2014

Number of times this article has been viewed

\author{
Ranjit Suresh Mandwe' \\ Swapna Puri \\ Shrikant Shingane' \\ Ganesh Pawar' \\ Vivek Ramdas Kolhe' \\ Atul Alsi ${ }^{3}$ \\ 'Oral and Maxillofacial Surgery \\ Department, VYWS Dental College \\ and Hospital, Amaravati, Maharashatra, \\ India; ${ }^{2}$ Orthodontia Department, SDK \\ Dental College and Hospital, Nagpur, \\ Maharashatra, India; ${ }^{3}$ Prosthodontics \\ Department, VYWS Dental \\ College and Hospital, Amaravati, \\ Maharashatra, India
}

Aims and objectives: To assess the effect of presurgical nasoalveolar molding (PNAM) therapy in the management of patients with nonsyndromic unilateral cleft lip and palate (UCLP).

Material and method: Ten patients with UCLP treated from 2009 to 2012. The initiation for PNAM treatment was 7 days and the average time of the treatment was 175 days. Measurements on patients and of casts were made, and statistical analysis was used to evaluate the changes in pre- and posttreatment measurements.

Results: Subsequent to PNAM treatment, there was a statistically considerable rise in cleft nostril height and columellar width. There was reduction in both intraoral cleft width and columellar deviation, which was significant statistically.

Conclusion: PNAM treatment reduces alveolar cleft width. It enhances symmetry of the nose by changing columellar angulation, preserving alar width bilaterally, gaining height of the nostril on the affected side, and increasing columellar length.

Keywords: unilateral cleft lip and palate, UCLP, presurgical nasoalveolar molding, PNAM, orthodontic resin, cleft lip

\section{Introduction}

The question of use of presurgical nasoalveolar molding (PNAM) treatment for patients with cleft lip and palate (CLP) remains an unanswered dispute. At the time of this study, there are two schools of thoughts for the management of CLP patients; one advocates the use of presurgical nasoalveolar molding and the other believes in surgical correction only. Even after performing multiple corrective surgeries on CLP patients, final outcome is questionable. The concern over final nasal form has given birth to the use of PNAM appliance in the management of CLP.

The hypothesis of PNAM treatment is conceptualized on Matsuo and Hirose's study that the nasal cartilage is still developing and is subject to repositioning within the first 6 weeks of life. ${ }^{1}$ Grayson et al described the first treatment protocol for PNAM. ${ }^{2}$ Even though there are a number of reports regarding the usefulness of PNAM in patients with unilateral CLP, there are few reports on its efficacy in patients with bilateral CLP. $^{2-8}$ The intention of this study was to find the outcome of PNAM appliance in the management of patients with unilateral CLP. The special emphasis of this study was on the effect that appliance has on nasal form and cleft segments.

\section{Materials and methods}

Ten patients with unilateral cleft lip and palate (UCLP) reported at the Department of Oral and Maxillofacial Surgery, from January 2009 to March 2012 were selected for 
PNAM treatment. The protocol was approved by the VYWS Dental College ethical committee and informed consent was obtained. Ten patients (four males and six females) with UCLP were selected for this study. Seven patients were with complete CLP and three infants were with partial CLP. Six patients had a cleft on the right side and four had a cleft on the left side.

The usual age of the patients for starting PNAM treatment was 7 days (range: 1-14 days) and the usual duration of treatment was 175 days (range: 90-260 days). In this study, patients with unilateral, nonsyndromic CLP were selected and included after the patient's family consented for the PNAM treatment. Systemically compromised patients were excluded from the study.

An alginate impression was taken of the newborn during the early visit. After preparation of a special tray, heavy bodied silicon material was used to take the final impression. The infant was held upside down and the impression tray was inserted into the oral cavity, which aided in precluding the tongue from falling back and permitted excess material to flow out of the oral cavity. Once the impression was set, it was taken out; the oral cavity was checked for remaining impression material. A precise cast was obtained by pouring the impression into dental stone (Figure 1).

\section{Appliance design}

All the undercuts and cleft space were blocked with block-out wax. A self-cure acrylic plate of $1.5 \mathrm{~mm}$ thickness, which was lined with soft tissue liner, was made. A retention button was fabricated on 22-gauge stainless steel wire, positioned anteriorly at an angle of approximately $45^{\circ}-50^{\circ}$ to the plate. As patients were having unilateral cleft, only one retention arm was built-in and placed in such a way that it stayed near

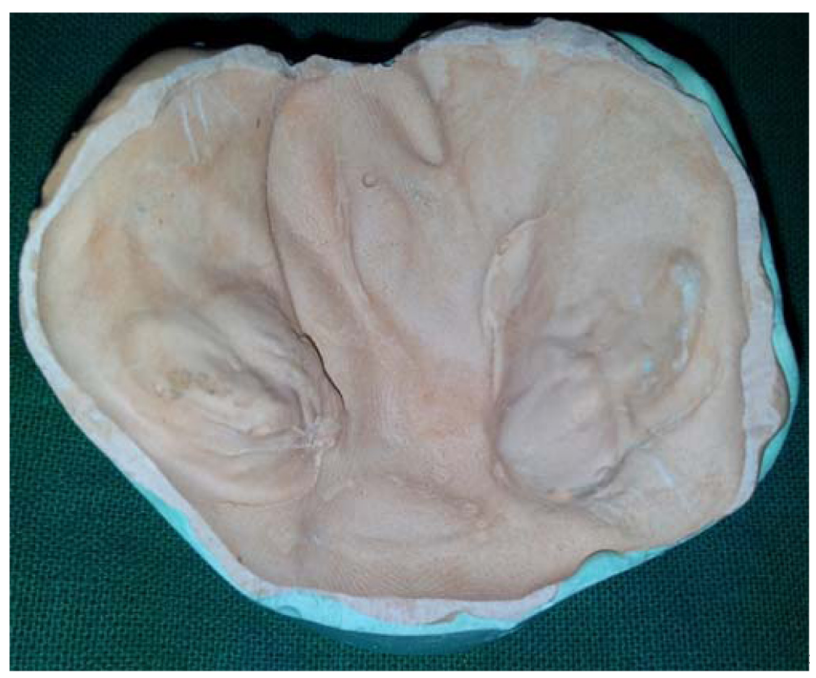

Figure I Pretreatment study model. to the inner aspect of the affected nostril and then was covered with orthodontic resin (Figure 2). The upright arrangement of the retention arm was positioned at the connection of the appliance and lower lip (Figures 3 and 4). When interalveolar cleft width reduced to $1 \mathrm{~cm}$, a nasal stent was added. Orthodontic elastics and adhesive tapes were used to facilitate effective positioning of the PNAM appliance.

\section{Appliance adjustments}

The inner side of the acrylic plate was relieved for alveolar segment approximation. Patients were kept under observation and every 14 th day of visits the appliances were adjusted. The progression of the alar cartilages into the nasal tip was accomplished by adding acrylic to the nasal stents. Increase in length of columella was achieved by combining action of the nasal stent and prolabial banding. Parents were educated on handling and wearing of appliances. Parents were also informed to add a thin layer of petroleum jelly on the nasal stent at the time of every insertion. Activation of the appliance continued till 6-8 months of age, ie, till the surgical repair.

When the intraoral cleft width (ICW) reduced to $<4 \mathrm{~mm}$ and ala of the nose on the cleft side relocated (Figures 5 and 6), the PNAM treatment was concluded. After completion of PNAM treatment, casts were obtained by taking intraoral impressions. Measurements were done on the casts and on the patients (Tables 1 and 2; Figures 7-12).

\section{Statistics}

All measurements were compared using paired $t$-tests. Statistical significance was determined at $P<0.05$.

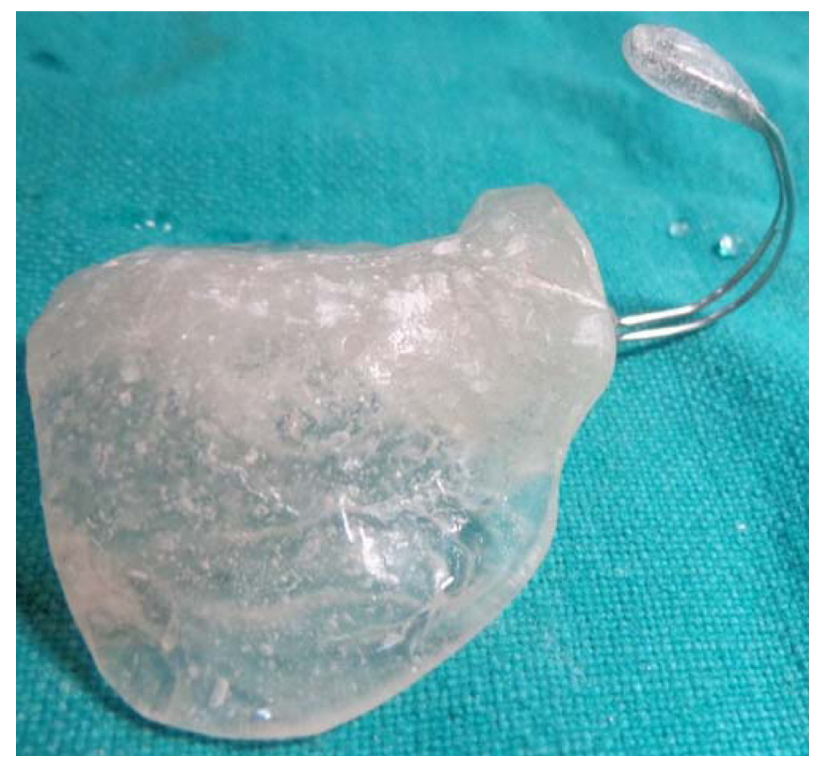

Figure 2 Nasoalveolar molding appliance. 


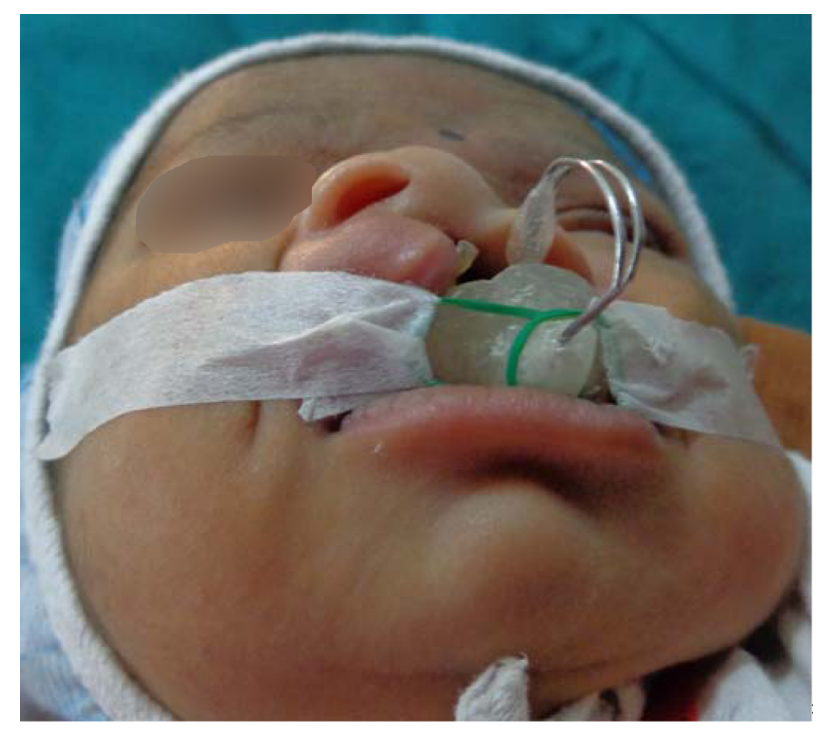

Figure 3 Positioning of nasal stent.

\section{Reliability}

Three arbitrarily chosen patients were remeasured and reanalyzed 2 days later by the same inspector. Two sets of measurements were compared using paired $t$-tests to examine the intra-observer error. Insignificant variation $(P<0.01)$ between the two sets of measurements was found.

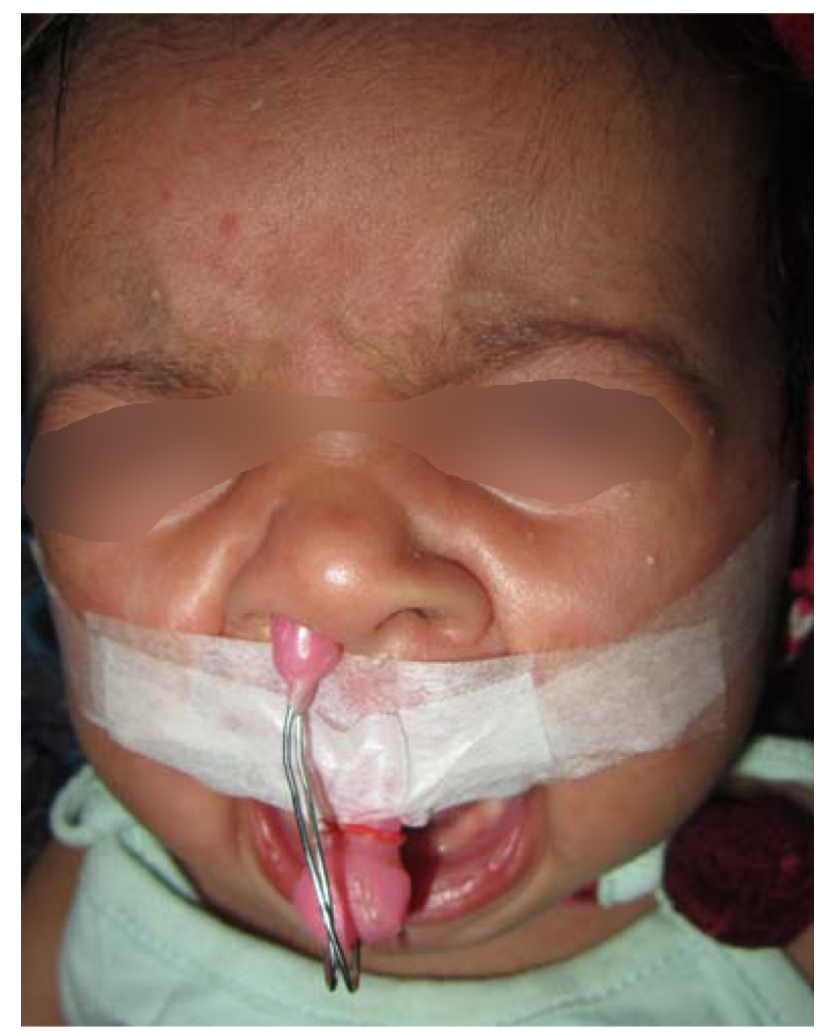

Figure 4 Prolabial banding with orthodontic bands and adhesive tapes.

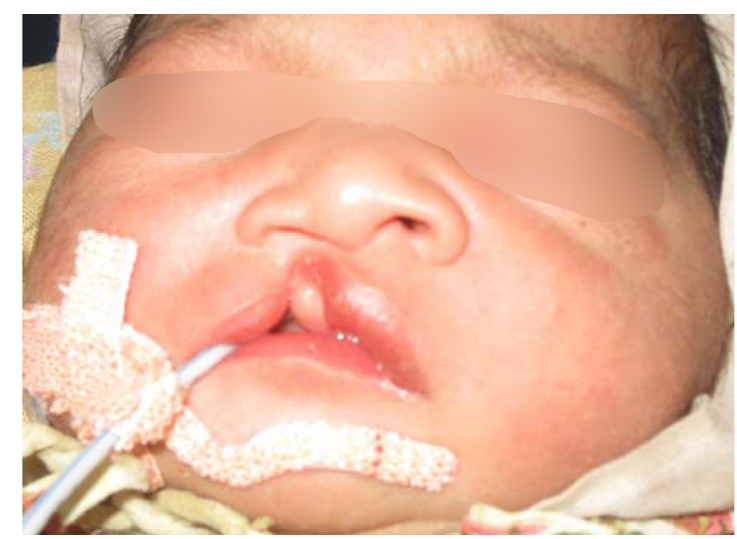

Figure 5 Before presurgical nasoalveolar molding treatment.

\section{Results}

Arch width remained significantly unchanged. Widths of cleft ranged from $5 \mathrm{~mm}$ to $17 \mathrm{~mm}$ at the initial visits. After PNAM, the ICW ranged from $0.5 \mathrm{~mm}$ to $11 \mathrm{~mm}$. The

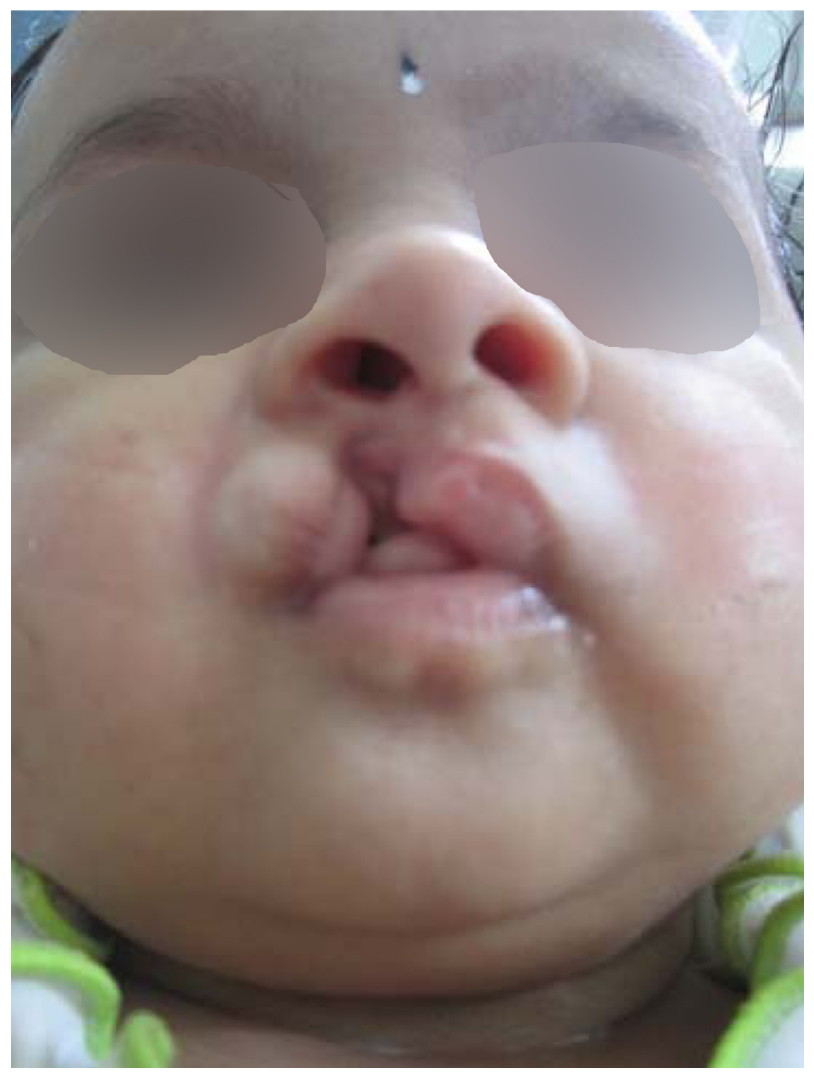

Figure 6 After presurgical nasoalveolar molding treatment.

Table I Measurements on casts

\begin{tabular}{ll}
\hline Measurements & Explanation \\
\hline Intraoral cleft width & Measurement between alveolar ridges \\
Intraoral arch width & Maximum horizontal measurement at \\
& crest of alveolar ridges \\
\hline
\end{tabular}


Table 2 Measurements on patients

\begin{tabular}{ll}
\hline Measurements & Explanation \\
\hline $\begin{array}{l}\text { Bialar width } \\
\text { Columellar width } \\
\text { Columellar length }\end{array}$ & $\begin{array}{l}\text { Measurement between the right and left ala of nose } \\
\text { Width of columella at base } \\
\text { Distance from base of columella to most anterior } \\
\text { and inferior point } \\
\text { Mostril height }\end{array}$ \\
$\begin{array}{l}\text { Maximum vertical length from floor to inner } \\
\text { aspect of ala of nose }\end{array}$ \\
$\begin{array}{l}\text { Maximum horizontal length at alar base } \\
\text { Columellar angle on } \\
\text { cleft side }\end{array}$ & $\begin{array}{l}\text { Angle formed by joining a line from nasal tip to } \\
\text { intercolumellar line and calculated from cleft side }\end{array}$ \\
\hline
\end{tabular}

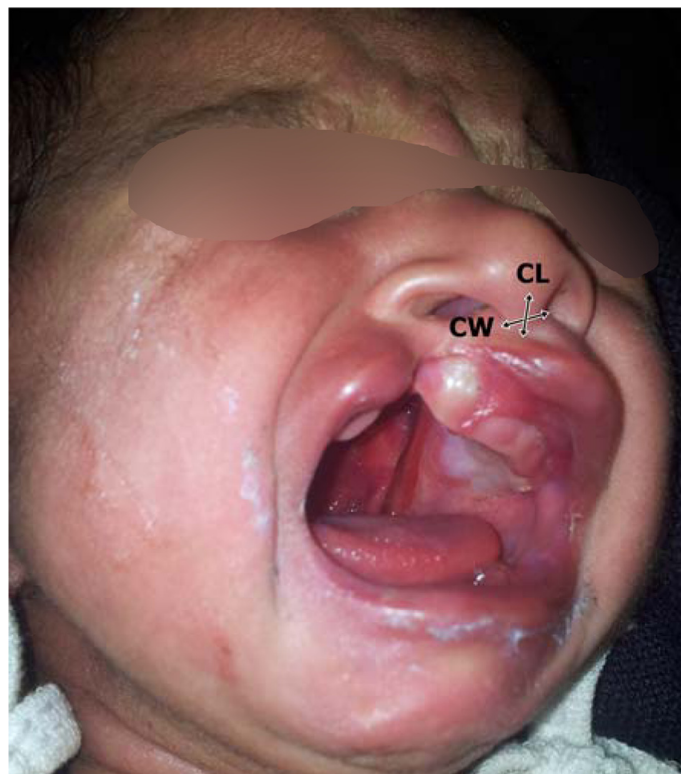

Figure 7 Columellar length $(\mathrm{CL})$ and columellar width $(\mathrm{CW})$ measurement.

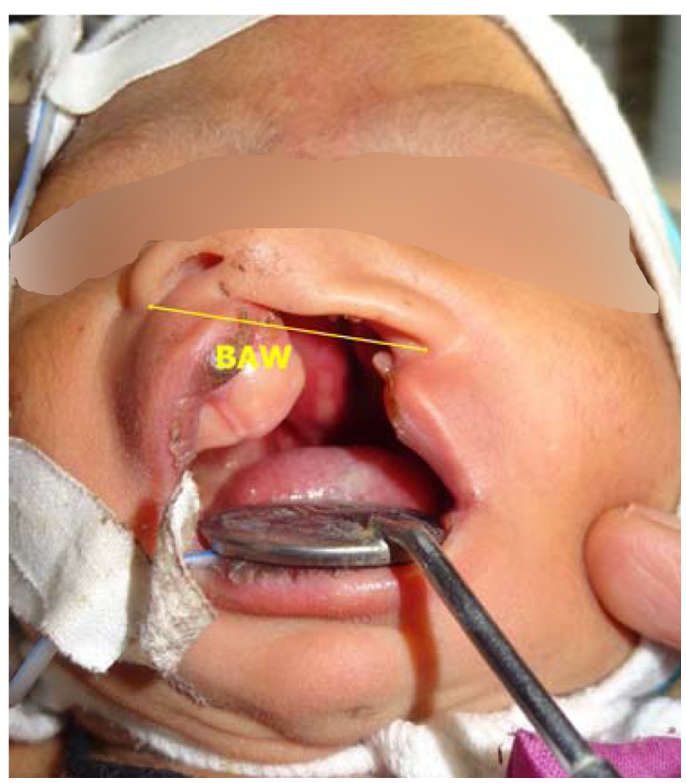

Figure 8 Bialar width (BAW) measurement.

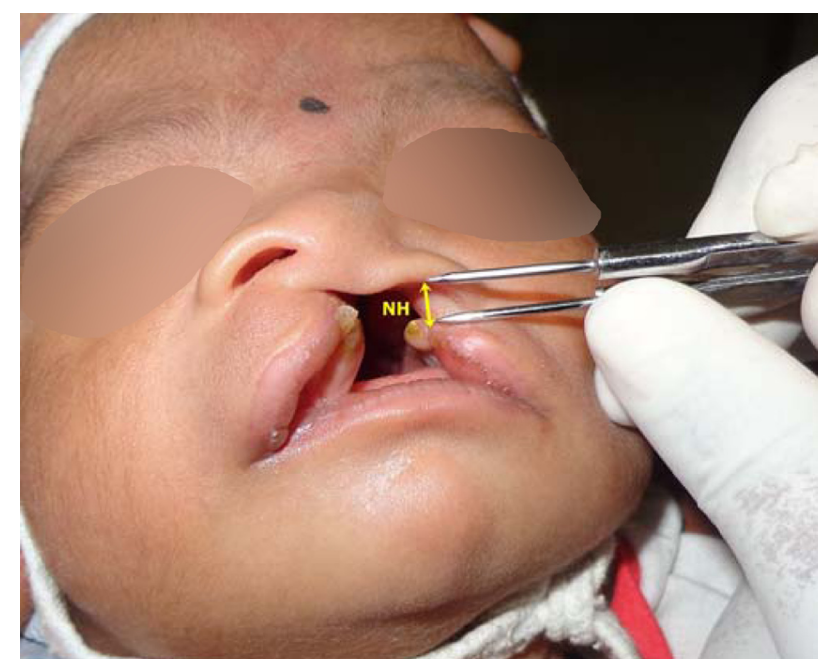

Figure 9 Nostril height $(\mathrm{NH})$ measurement.

change in the ICW varied individually. In the best case, alveolar gap width changed from $15 \mathrm{~mm}$ at the initial visit to $5 \mathrm{~mm}$ before cheiloplasty. In the worst case, cleft width was reduced by only $3 \mathrm{~mm}$, from $13 \mathrm{~mm}$. On comparing ten complete-cleft newborn infants with three incomplete-cleft newborn infants, there was comparatively little change in ICW and complete-cleft newborn infants consumed more time for the treatment.

The change in bialar width was statistically significant (Table 3). Measurements showed a statistically significant increase in bialar width, which was $4.04 \mathrm{~mm}$. Furthermore,

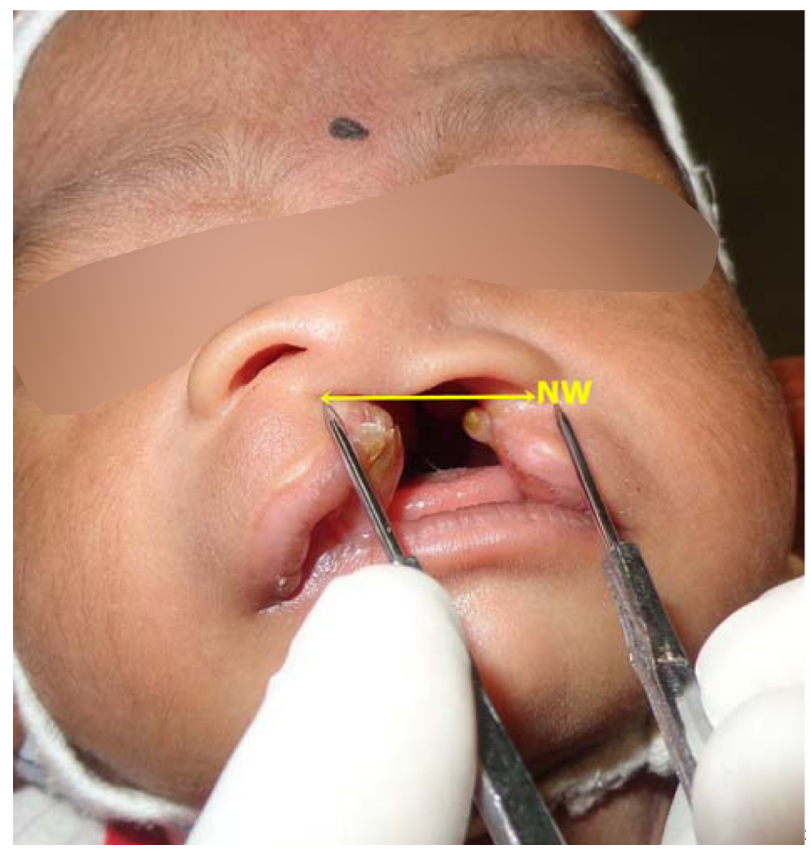

Figure 10 Nostil width (NW) on cleft side measurement. 


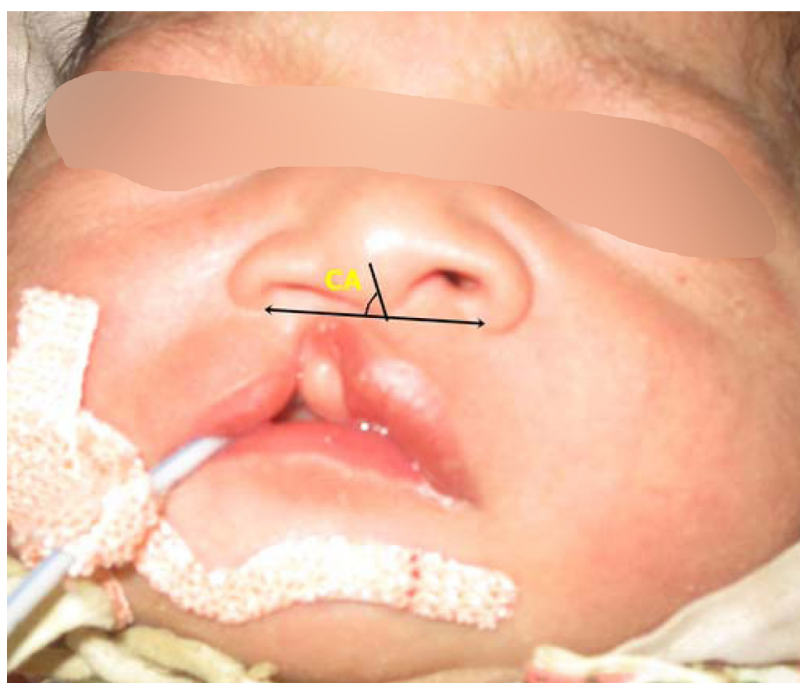

Figure I I Columellar angle (CA) measurement.

columellar length, which changed from $3.43 \mathrm{~mm}$ to $6.95 \mathrm{~mm}$ before cheiloplasty, was also statistically significant. But change in columellar width was not significant. Nostril heights were improved on the affected side (average $3.27 \mathrm{~mm}$ ) after PNAM. There was little difference in change in nostril height between complete- and partial-cleft neonates. There was an increase in the nostril width of the cleft, but the number was statistically insignificant. Columellae were deviated to the unaffected side with an average of $50.12^{\circ}$ on initial visit. The columella became more upright $\left(67.6^{\circ}\right)$ before cheiloplasty and almost to a right angle after cheiloplasty. Significant differences were noted during comparison at each time interval.

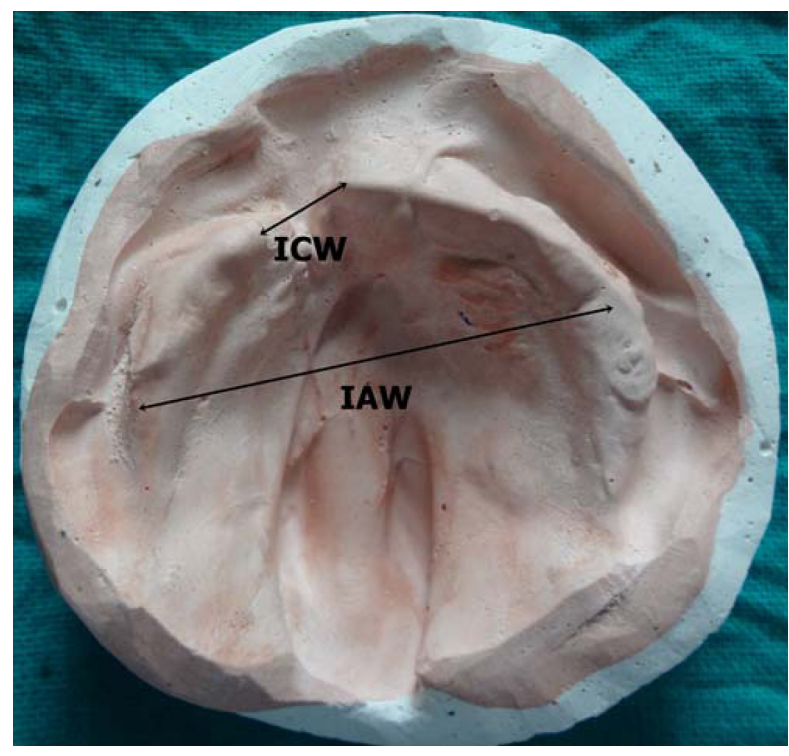

Figure 12 Measurements on cast: inter cleft width (ICW), inter alveolar width (IAW).
Table 3 Pre- and post-PNAM results

\begin{tabular}{ccll}
\hline & Pre-PNAM & Post-PNAM & Difference \\
\hline \multicolumn{2}{r}{ Intraoral measurements } \\
IAW & 38.12 & & \\
ICW & 14.03 & 39.21 & 1.09 \\
Extraoral measurements & 7.82 & -6.21 \\
BAW & 29.28 & & \\
CW & 3.36 & 31.04 & 1.76 \\
CL & 3.43 & 4.13 & 1.23 \\
NH & 2.51 & 6.95 & 3.42 \\
NW & 12.32 & 5.78 & 3.27 \\
CA & $50.12^{\circ}$ & 13.51 & 1.19 \\
\hline
\end{tabular}

Abbreviations: BAW, bialar width; CA, columellar angle; CL; columellar length; $\mathrm{CW}$; columellar width; IAW, inter alveolar width; ICW, inter cleft width; $\mathrm{NH}$, nostril height; NW, nostil width; PNAM, presurgical nasoalveolar molding.

\section{Discussion}

Treatment of PNAM should be initiated as soon as possible after birth. During the perinatal period, maternal estrogen rises, which triggers an increase in hyaluronic acid. Hyaluronic acid reduces cartilage, ligaments, and connective tissue elasticity by breaking down the intracellular matrix. ${ }^{9}$ The amount of plasticity in neonatal cartilage is highest after birth and gradually reduces as infants grow. This might be because of high levels of hyaluronic acid in estrogen that was transferred from the mothers to the infants. The cartilage subsequently loses its pliability at around 6 weeks. Therefore, PNAM is most successful during the first 3-4 months of life. ${ }^{1}$

In accordance with the chondral-modeling hypothesis, nasoalveolar molding (NAM) may be acting as a catalyst that stimulates the chondroblasts, producing interstitial expansion and improvements in nasal form. ${ }^{10}$

In this study, NAM appliance is successful in guiding separated maxillary alveolar segments into a normal position and cleft width reduced significantly, but a complete osseous bridge is not seen.

Even though surgeons try to perform early lip and palate repair, achieving optimum nasal shape and form has always been an arduous task. The long-term results of nasal reconstruction at the time of primary lip repair are still questionable. Millard, ${ }^{11}$ Millard and Morovic, ${ }^{12}$ and Grayson et $\mathrm{al}^{2}$ proposed that definitive repair of cleft lip and nose should be done as early as possible. The idea of correcting the nostril cartilage symmetry before primary lip repair was advocated by Matsuo et al. ${ }^{1}$ However, their device could be applied only to individuals with incomplete clefts, who usually demonstrate a lesser degree of nostril asymmetry than do those with complete clefts. Grayson et al first introduced a PNAM device in 1993, and the technique can be applied successfully to patients with complete CLP. ${ }^{2}$ 
The aims of PNAM in the unilateral cleft patients are to guide separated maxillary alveolar segments into normal position; reduce cleft width; correct the malpositioned nasal cartilages, columella and philtrum; bring the columella toward the midsagittal plane; increase columella length; improve symmetry of the nostril apertures; and reduce scar formation after cheiloplasty. ${ }^{2}$ Recent clinical studies support the benefits of PNAM or alveolar molding alone. ${ }^{2,14,15}$ By reducing the alveolar gap in combination with gingivoperiosteoplasty, PNAM decreases the need for alveolar bone graft. ${ }^{14}$ PNAM could reduce the rate of secondary alveolar bone grafts $>60 \%$ during mixed dentition, and the procedure would not affect growth of the face. ${ }^{2}$ Approximations of the lip and alveolar cleft via alveolar molding minimize lip tension before and after cheiloplasty, thereby reducing scar formation. ${ }^{2}$ By adding the nasal molding to alveolar molding, the treatment effects are additive in terms of esthetics and function.

Maull et al reported a long-term study demonstrating improvement of nasal symmetry with PNAM, as compared with presurgical alveolar molding alone without nasal stenting (control group). Their results indicated that PNAM considerably improve the overall shape of the nose. ${ }^{15}$

In this study, the results demonstrated significant reduction in cleft width, nostril height and width after cheiloplasty, but in larger cleft width (ICW $\geq 15 \mathrm{~mm}$ ), it failed to achieve optimum nasal changes in terms of length, form, and symmetry. Although PNAM successfully increased nostril height on the affected side, the nostril was still wider. This is because orbicularis oris affects nasal morphology by displacing the insertion of the columella toward the noncleft side and hypoplasia of the lesser segment as well as a deficiency of maxillary bone. ${ }^{16}$ A missing or lowered nasal floor can be corrected only by cheiloplasty, which would make the nostrils even more symmetrical in terms of height, width, and columella angle.

In this study, factors contributing to alveolar gap reduction would be 1) relief on the inner side of the acrylic molding plate at the direction of segment approximation; 2) force of lip taping; and 3) soft tissue force created on cleft segments at the time of sucking while appliance is in situ. Alveolar gap was reduced in size when room was created by gradually relieving the inner side of a passive acrylic molding plate for approximation of a major segment on biweekly visits. The molding plates passively pushed the greater segment of the alveolar ridges toward the lesser segments during sucking. Lip taping offered outer pressure to approximate the upper lip and alveolar gap, to decrease width of the nasal base, and to permit the lip segments to be anatomically located, which assist lip repair under less tension, so that healing and scarring can be minimized.

\section{Conclusion}

Nasoalveolar modeling is advantageous for achieving nasal symmetry and cleft width reduction in unilateral cleft patients, but it requires frequent visits and parent's and patient's compliance. This is a small study, and to validate further, we recommend continuation of study with a large sample size and long-term follow-up.

\section{Disclosure}

The authors report no conflicts of interest in this work.

\section{References}

1. Matsuo K, Hirose T. Preoperative non-surgical over-correction of cleft lip nasal deformity. Br J Plast Surg. 1991;44:5-11.

2. Grayson BH, Santiago PE, Brecht LE, Cutting CB. Presurgical nasoalveolar molding in infants with cleft lip and palate. Cleft Palate Craniofac J. 1999;36:486-498.

3. Bennun RD, Perandones C, Sepliarsky VA, Chantiri SN, Aguirre MI, Dogliotti PL. Nonsurgical correction of nasal deformity in unilateral complete cleft lip: a 6-year follow-up. Plast Reconstr Surg. 1999;104: 616-630.

4. Cho B. Unilateral complete cleft lip and palate repair using lip adhesion and passive alveolar molding appliance. J Craniofac Surg. 2001;12:148-156.

5. Pfeifer TM, Grayson BH, Cutting CB. Nasoalveolar molding and gingivoperiosteoplasty versus alveolar bone graft: an outcome analysis of costs in the treatment of unilateral cleft alveolus. Cleft Palate Craniofac J. 2002;39:26-29.

6. Da Silveira AC, Oliveira N, Gonzalez S, et al. Modified nasal alveolar molding appliance for management of cleft lip defect. J Craniofac Surg. 2003;14:700-703.

7. Yang S, Stelnicki EJ, Lee MN. Use of nasoalveolar molding appliance to direct growth in newborn patient with complete unilateral cleft lip and palate. Pediatr Dent. 2003;25:253-256.

8. Liou EJ, Subramanian M, Chen PK, Huang CS. The progressive changes of nasal symmetry and growth after nasoalveolar molding: a three-year follow-up study. Plast Reconstr Surg. 2004;114:858-864.

9. Raffat A, Ijaz A. Premaxillay retraction in bilateral complete cleft lip and palate with custom made orthopaedic plate having anterior acrylic ring. J Pak Med Assoc. 2009;59:376.

10. Hamrick MW. A chondral modeling theory revisited. J Theor Biol. 1999;201:201-208.

11. Millard DR. Early correction of the unilateral cleft lip nose. Plast Reconstr Surg. 1982;70:64-73.

12. Millard DR, Morovic CG. Primary unilateral cleft nose correction: a 10-year follow-up. Plast Reconstr Surg. 1998;102:1331-1338.

13. Matsuo K, Hirose T, Tomono T, et al. Nonsurgical correction of congenital auricular deformities in the early neonate: a preliminary report. Plast Reconstr Surg. 1984;73:38-51.

14. Santiago PE, Grayson BH, Cutting CB, Gianoutsos MP, Brecht LE, Kwon SM. Reduced need for alveolar bone grafting by presurgical orthopedics and primary gingivoperiosteoplasty. Cleft Palate Craniofac J. 1998;35:77-80.

15. Maull DJ, Grayson BH, Cutting CB, et al. Long-term effects of nasoalveolar molding on three-dimensional nasal shape in unilateral clefts. Cleft Palate Craniofac J. 1999;36:391-397.

16. Da Silveira AC. Modified nasal alveolar molding appliance for management of cleft lip defect. J Craniofac Surg. 2003;14(5): 700-703. 


\section{Publish your work in this journal}

Clinical, Cosmetic and Investigational Dentistry is an international, peer-reviewed, open access, online journal focusing on the latest clinical and experimental research in dentistry with specific emphasis on cosmetic interventions. Innovative developments in dental materials, techniques and devices that improve outcomes and patient satisfaction and preference will be highlighted. The manuscript management system is completely online and includes a very quick and fair peerreview system, which is all easy to use. Visit http://www.dovepress. com/testimonials.php to read real quotes from published authors.

Submit your manuscript here: http://www.dovepress.com/clinical-cosmetic-and-investigational-dentistry-journal 